\title{
Managing healthcare delivery system to fight the COVID-19 epidemic: experience in Japan
}

\author{
Ruoyan Gai ${ }^{1 *}$ and Makoto Tobe ${ }^{2}$
}

\begin{abstract}
Amid the global pandemic of a novel Coronavirus Disease 2019 (COVID-19), healthcare delivery system is being stretched. In Japan, rapid spread of the epidemic brings hospitals to the brink of exhaustion. This commentary aims to briefly review related policies of Japan in managing healthcare delivery system. Among the relevant actions, strengthening the hospitalized care is emphasized to save lives. Despite of limitations, the policies show a success in preventing a collapse of healthcare delivery system and skyrocketing mortality from happening so far. On the other hand, huge concerns remain if the infections continue to rapidly increase. The experience in Japan indicates the urgency of planning of healthcare delivery system, mobilizing all relevant social sectors by consensus, and guiding people with calm manner based on the best shared knowledge and evidences.
\end{abstract}

\section{Background}

The pandemic of a novel Coronavirus Disease 2019 (COVID-19) caused by the severe acute respiratory syndrome coronavirus 2 (SARS-CoV2) has posed a severe global crisis. In Japan, the incidence is escalating, causing a large number of community transmission. As of April 8, 2020, the time point that the statement of emergency is initiated, the number of domestic confirmed infection cases reaches up to 4168, with 81 deaths (Fig. 1). The policies in Japan highlight the planning of healthcare delivery system, in particular the prevention of an "overshoot" in hospitals. To this end, a crucial lesson has been learned from Wuhan, China, where hospitals once melted down at the beginning as the result that patients were overwhelmingly seeking healthcare, and consequently those severe cases urgently needing inpatient care cannot be hospitalized. The exhaustion of healthcare delivery system is one of the reasons for the incredibly high mortality rate in that period [1]. The overcrowded and contaminated environment of hospitals exposed a large population to high risk of the infection,

\footnotetext{
* Correspondence: gai-ruoyan@ipss.go.jp

${ }^{1}$ National Institute of Population and Social Security Research, Tokyo, Japan Full list of author information is available at the end of the article
}

further exacerbating the epidemic. Similar conditions now also occur in seriously hit countries such as Italy and Spain, where the crude mortality rate due to COVID-19 largely exceeds the global average level of $3.4 \%$ [2]. Confronting the epidemic, it should be noted that the capacity of healthcare delivery system is not unlimited and consequently it entails a series of policies to avoid a surge of the infected. This commentary focuses on adaptation of healthcare delivery system for the containment of COVID-19 in Japan, for knowledge sharing with the global society. The major related measures adopted in Japan are outlined.

\section{Guiding healthcare seeking}

As COVID-19 is listed to be a designated infectious disease in the Infectious Diseases Control Law, the patients are rendered to the hospitalized care in the designated facility in general. On the other hand, the overwhelming healthcare seeking may lead to a collapse of healthcare delivery system as mentioned above. In this regard, the basic policies for COVID-19 control emphasized the hospitalized care for the severe / critical case based on previous experiences [3], and recommended people with mild flu-like symptoms to stay at home first and seek

(c) The Author(s). 2020 Open Access This article is licensed under a Creative Commons Attribution 4.0 International License, which permits use, sharing, adaptation, distribution and reproduction in any medium or format, as long as you give appropriate credit to the original author(s) and the source, provide a link to the Creative Commons licence, and indicate if changes were made. The images or other third party material in this article are included in the article's Creative Commons licence, unless indicated otherwise in a credit line to the material. If material is not included in the article's Creative Commons licence and your intended use is not permitted by statutory regulation or exceeds the permitted use, you will need to obtain permission directly from the copyright holder. To view a copy of this licence, visit http://creativecommons.org/licenses/by/4.0/. 
The expanding epidemic of COVID-19 in Japan

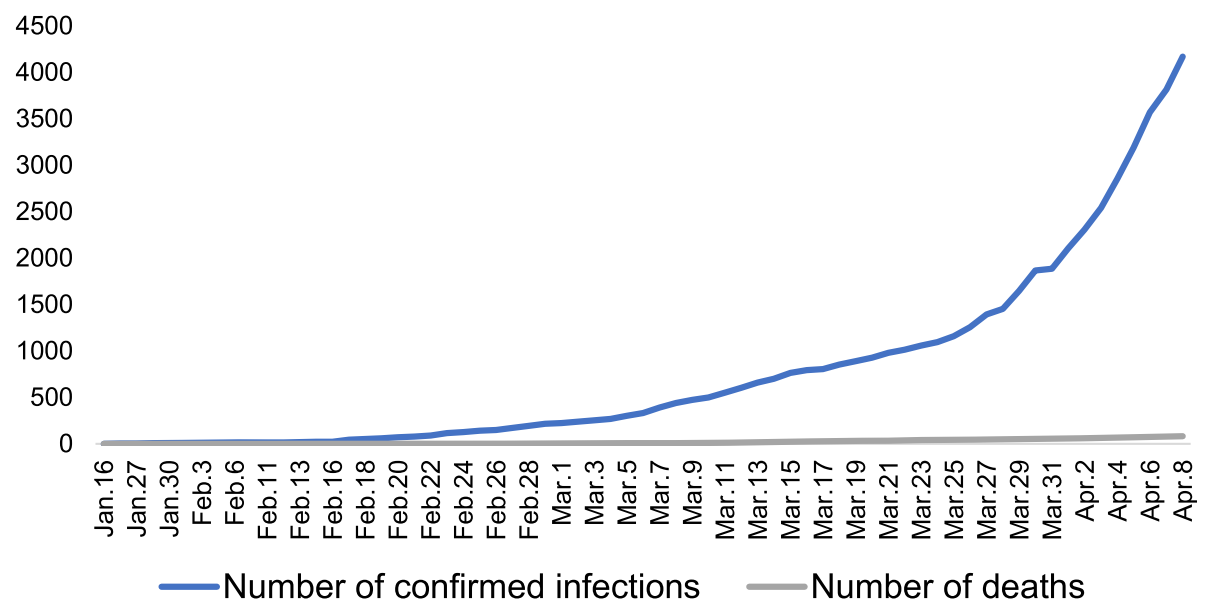

Fig. 1 the expanding epidemic of COVID-19 in Japan. Data derive from the daily report of Ministry of Health, Labour and Welfare of Japan

medical care after consulting the call center or a family doctor [4]. After the declaration of state of emergency, Tokyo metropolitan government decides to move patients with mild or no symptom (except the elderly, those with pre-existing health conditions and pregnant women) from hospitals to the assigned facilities to increase bed capacities with serious cases for COVID-19. To mitigate mortality and morbidity, it is worthy to note that the elderly, those with pre-existing diseases and pregnant women are specially considered for healthcare delivery, including detection and inpatient-based treatment, because of their vulnerability $[3,5]$.

\section{Planning the implementation of the detection test} In Japan, because of a limited laboratory capacity, priorities are given to determining cases requiring an inpatient care and tracing the cluster transmission, rather than to exploring the infection in the overall population through massive screening. Meanwhile, the test method based on polymerase chain reaction (PCR) has a limited accuracy [6], especially when the test is used for a large cohort of population. A relevant proportion of false positive is prone to cause spread of infection from these tested negative but truly positive, whereas a large number of false negative leads to unnecessary occupation of limited healthcare resources that could be otherwise for severe cases.

With regard to this, the implementation of detection test based on PCR has been scheduled by the call center for consultation, which was established within each health center of prefectures and government-designated cities right in early February 2020. The criteria of seeking consultation are stipulated and updated, with consideration of high-risk population, such as the elderly, those with pre-existing health conditions and pregnant women. The call-center-based consultation system plays a key role of guidance of healthcare seeking and referral. It also provides a clue to capture the overall epidemic scale in the country. As the laboratory capacity has gradually improved, the PCR test has been included into benefit package of the social health insurance schemes and offered under physician's discretion since March 2020.

\section{Improving the capacity of healthcare delivery system}

The capacity of healthcare delivery system is challenged by rapidly growing severe / critical cares [7]. In Japan, it is largely calling for wide negotiations and collaborations among the national and local governments, manufacturers and healthcare providers. Since emerging of COVID-19, the national government has urged local authorities to prepare to secure hospital beds, intensive care unit and medical equipment in hospitals, especially for those not originally designated and specialized for infectious diseases. Guidelines for infection control measures developed by the Ministry of Health, Labour and Welfare help to inform hospitals and health professionals. The government has also mobilized the manufacturing to ensure the supply chain of medical equipment and materials. On the other hand, it is reported that difficulties nevertheless remain in local authorities to offer the number of beds equivalent to the estimates of the expert panel assigned by the health ministry during the peak period of the epidemic [8]. Besides limited hospital beds and materials, a shortage of doctors, especially infectious disease specialists remain a huge concern $[7,9]$. The high risk of iatrogenic infection and lack of support to child care during school closure may further deteriorate the situation. 


\section{Suppressing the scale of the epidemic}

The limitation in the capacity of healthcare delivery system suggest an urgency to suppress the scale of the epidemic. In Japan, routine hygiene behaviors and health literacy of self-motivated and well-informed public compose the first line of defeating COVID-19. Effective measures such as mask wearing [10], hand washing and health management are well penetrated in daily life. Since the outbreak, clusters and contacts are closely traced by the public health officers to generate the firsthand data source for evaluation by the expert panel of MHLW. Then a number of measures have been implemented with engagement of various stakeholders, including different governmental sectors, expert panels, local authorities, schools, industries and civil society, such as a nationwide school closure, promotion of telecommuting, staggered commuting time and voluntary restraints. Knowledge on pathological, epidemiological and clinical characteristics of the virus and disease and public health measures are constantly updated to the public. Social distancing is being reinforced. On the other hand, a lockdown as the most radical measure of social distancing may lag behind because of lack of legal force, suggesting the containment in Japan is largely relying on consensus, self-motivation and empowerment of the public.

\section{Boosting public understanding and consolidated trusts}

As mentioned, underpinning the promotion of these policies are public understanding and consolidated trusts. As public health measures are not compulsory but voluntary in the country, the government is striving to get consensus and to consolidate the trusts from relevant stakeholders including local authorities and the public by providing information that is accurate, prompt and easy to understand and practice. The current policies also emphasize a thoughtful consideration of the growing concerns and fears in public. Especially at this moment when public anxiety and fear are spreading together with the growing number of infections, effective communicating channels to the public are necessary to promote public understanding and encourage calmness.

\section{Conclusion}

In Japan, preventing the exhaustion of healthcare delivery system and softening the spike of the epidemic are regarded to be of paramount importance. These policies have limitations in testing, resource mobilizing and social distancing. However, the number of death cases since the emerging of COVID-19 suggests these prioritybased measures have partly contributed to deferring the occurrence of the spike, adapting healthcare delivery system and saving lives so far. It should be recognized that, on the other hand, concerns remain in the capacity of healthcare delivery system if the epidemic continues to rapidly progress. To this end, dealing with the crisis further requires an agile and coordinative leadership to consolidate consensus and trusts. The experiences in Japan to date indicates the importance of (1) preparing healthcare delivery system for the epidemic, (2) mobilizing all relevant stakeholders and social sectors by the consensus, and (3) guiding people with calm manner based on the best shared knowledge and evidence, and all that are attributable to contingency planning and preparedness at early stage.

\section{Abbreviations}

COVID-19: Coronavirus Disease 2019; MHLW: Ministry of Health, Labour and Welfare; PCR: Polymerase chain reaction; SARS: The severe acute respiratory syndrome; SARS-CoV2: The severe acute respiratory syndrome coronavirus 2; WHO: World Health Organization

\section{Acknowledgements}

The opinions presented in this commentary are based on individual view and do not reflect that of National Institute of Population and Social Security Research, Japan and that of Japan International Cooperation Agency.

\section{Authors' contributions}

Dr. Ruoyan Gai concepted and wrote the manuscript. Dr. Makoto Tobe then added essential materials for interpretation and revised the manuscript. The authors have approved the submitted version.

\section{Authors' information}

Not applicable.

Funding

Not applicable.

Availability of data and materials

Not applicable.

Ethics approval and consent to participate

Not applicable.

Consent for publication

Not applicable.

Competing interests

Not applicable.

\section{Author details}

${ }^{1}$ National Institute of Population and Social Security Research, Tokyo, Japan.

${ }^{2} J a p a n$ International Cooperation Agency, Tokyo, Japan.

Received: 11 March 2020 Accepted: 29 April 2020

Published online: 13 May 2020

\section{References}

1. Mizumoto K, Chowell G. Estimating risk for death from 2019 novel coronavirus disease, China, January-February 2020. Emerg Infect Dis. 2020; 26(6). https://doi.org/10.3201/eid2606.200233 [Epub ahead of print].

2. World Health Organization. WHO-AUDIO Emergencies Coronavirus Press Conference 03 March 2020. Available at: https://www.who.int/docs/defaultsource/coronaviruse/transcripts/who-audio-emergencies-coronavirus-pressconference-full-03mar2020-final.pdf. Assessed 8 Apr 2020.

3. Verity R, Okell LC, Dorigatti l, et al. Estimates of the severity of coronavirus disease 2019: a model-based analysis. Lancet Infect Dis. 2020. https://doi. org/10.1016/S1473-3099(20)30243-7 [Epub ahead of print].

4. Ministry of Health, Labour and Welfare, Japan. Basic Policies for Novel Coronavirus Disease Control (Released on 25 February 2020). Available at: 
https://www.mhlw.go.jp/content/10200000/000603610.pdf. Assessed 8 Apr 2020.

5. Zhang $L$, Jiang $Y$, Wei M, et al. Analysis of the pregnancy outcomes in pregnant women with COVID-19 in Hubei Province (in Chinese). Zhonghua Fu Chan Ke Za Zhi. 2020;55(0):E009. https://doi.org/10.3760/cma.j.cn11214120200218-00111 [Epub ahead of print].

6. Zhang R, Li JM. The way to reduce the "false negative results" of 2019 novel coronavirus nucleic acid detection (in Chinese). Zhanghua Yi Xue Za Zhi. 2020;100:E008

7. Legido-Quigley H, Asgari N, Teo YY, et al. Are high-performing health systems resilient against the COVID-19 pandemic? Lancet. 2020;395(10227): 848-50.

8. NHK Online News on 27 March 2020. Available at: https:/www3.nhk.or.jp/ news/html/20200327/k10012353801000.html. Assessed 8 Apr 2020.

9. Organization for Economic Cooperation and Development (OECD). Doctors per 1000 inhabitants in 2018. Data available at: https://data.oecd.org/ healthres/doctors.htm. Assessed 8 Apr 2020.

10. Feng S, Shen C, Cowling BJ, et al. Rational use of face masks in the COVID19 pandemic. Lancet Respir Med. 2020. https://doi.org/10.1016/S22132600(20)30134-X [Epub ahead of print].

Ready to submit your research? Choose BMC and benefit from:

- fast, convenient online submission

- thorough peer review by experienced researchers in your field

- rapid publication on acceptance

- support for research data, including large and complex data types

- gold Open Access which fosters wider collaboration and increased citations

- maximum visibility for your research: over $100 \mathrm{M}$ website views per year

At BMC, research is always in progress.

Learn more biomedcentral.com/submissions 